\title{
RUMAH GADANG SEBAGAI LAMBANG DEMOKRASI SUKU MINANGKABAU DI SUMATERA UTARA
}

\author{
Muhammad Azhar Faturahman ${ }^{1}$, Muhammad Yusvado A $\mathrm{H}^{2}$, Silvia Rini Putri ${ }^{3}$ \\ 1,2,3 Institut Teknologi Bandung \\ ${ }^{1} 13519020 @$ std.stei.itb.ac.id \\ 210619024@mahasiswa.itb.ac.id \\ 319019164@mahasiswa.itb.ac.id
}

\begin{abstract}
The ethnic of Minangkabau is known for their competency in implementing social and cultural values. Minangkabau is one of the ethnic that is upholding egalitiarian and democracy system. One of their cultures related is deliberation to achieve consensus within the community. The deliberation process is done stagely by holding conferences inside one of their custom houses or known as gadang house. Gadang house is very symbolic to the Minangkabau ethnic and carries important social and cultural values. As is well known, deliberation or discussion has an important role in Indonesia's democracy system. This study aims to discuss and discover the meaning and values behind Minangkabau's custom house and how it impacts the effectiveness of the deliberation process by its relevance as a symbol to represent democracy values in the Minangkabau community. The method used in this study is descriptive analysis by performing literature study. According to the result of the study, authors expect to expand insight and knowledge of Indonesian people with Minangkabau culture and its implementation of democracy values in daily life.
\end{abstract}

Keywords : Culture, Minangkabau, Custom House, Democracy

\begin{abstract}
Abstrak - Masyarakat suku Minangkabau dikenal sebagai salah satu suku yang memiliki menjunjung tinggi nilai-nilai sosial dan budaya. Salah satu kebudayaan masyarakat suku Minangkabau yang erat kaitannya dengan demokrasi adalah pelaksanaan musyawarah untuk mufakat dalam. Musyawarah oleh masyarakat Minangkabau dilakukan secara bertahap dan dalam beberapa pertemuan di rumah adat gadang atau balai adat. Dalam konsep demokrasi di Indonesia, musyawarah merupakan hal yang tidak dapat dipisahkan. Penelitian ini bertujuan untuk mengetahui makna dari rumah adat gadang serta seberapa besar pengaruhnya sebagai lambang yang merepresentasikan nilai-nilai demokrasi pada masyarakat Minangkabau. Metode yang digunakan dalam penelitian ini adalah deskriptif analisis dengan melakukan studi literatur. Dari hasil penelitian yang sudah dilakukan, penulis berharap dapat menambah wawasan dan ilmu pengetahuan kepada masyarakat Indonesia akan kearifan budaya Nusantara dalam menjalankan demokrasi di dalam kehidupan sehari-hari.
\end{abstract}

Kata kunci : Kebudayaan, Minangkabau, Rumah Adat, Demokrasi

\section{PENDAHULUAN}

Negara Kesatuan Republik Indonesia (NKRI) merupakan negara yang menganut sistem demokrasi dalam menjalankan pemerintahannya. Konsep demokrasi di Indonesia memiliki ciri khas tersendiri, yaitu adanya prinsip musyawarah untuk mufakat sebagai landasan dalam pelaksanaan kehidupan berbangsa dan bernegara. Prinsip ini telah melekat pada bangsa Indonesia sejak lama. Muzaqqi (2012) menjelaskan bahwa sebelum datangnya penguasa asing, di Indonesia telah memiliki sistem pemerintahan demokrasi-desa yang menekankan pada musyawarah-mufakat dan bersendi pada partisipasi rakyat.

Hanafi (2013) dalam kajiannya menjelaskan bahwa musyawarah mufakat di Indonesia telah menjadi sifat kehidupan masyarakat asli Indonesia dan memiliki esensi yang sangat penting dalam penerapan nilai pancasila dan demokrasi pada kehidupan bermasyarakat, dengan musyawarah dapat ditemukan cara untuk menyelesaikan suatu konflik ataupun cara mempersatukan berbagai pemikiran dan golongan karena diberikannya hak 
kebebasan dalam berpendapat dan memberikan kritik bagi setiap individu. Musyawarah menjaga keutuhan NKRI sebagai negara Bhinneka Tunggal Ika yang memiliki berbagai suku bangsa dengan keberagaman agama, bahasa, dan budaya.

Dari berbagai suku bangsa di Indonesia terdapat salah satu suku yang telah memegang prinsip demokrasi sejak dahulu, yaitu suku Minangkabau. Malik (2016) mengemukakan bahwa masyarakat suku Minangkabau dikenal sebagai masyarakat yang menjunjung tinggi adat istiadat dan memiliki nilainilai kebudayaan dan sosial yang tinggi. Salah satu adat masyarakat suku Minangkabau yang erat kaitannya dengan nilai-nilai demokrasi adalah bermusyawarah untuk mencapai kesepakatan. Kebiasaan dalam bermusyawarah ini tidak lepas dari peran lingkungan mereka yang mendukung dalam kegiatan tersebut.

Hasil lain dari kebudayaan masyarakat suku Minangkabau yang berpengaruh besar dalam pelaksanaan musyawarah adalah rumah gadang. Rumah gadang memiliki arti yang sangat penting bagi masyarakat Minangkabau, selain sebagai tempat tinggal rumah gadang juga berfungsi sebagai lambang eksistensi masyarakat Minang, tempat melakukan upacara adat, dan yang paling penting untuk dibahas saat ini adalah sebagai tempat musyawarah. Rumah gadang memiliki tata ruang rumah gadang memiliki nilai-nilai dan makna tertentu yang selaras dengan fungsi rumah tersebut (Marthala, 2013).

Sebagai negara demokrasi yang menjunjung tinggi kebebasan berpendapat sekaligus sebagai negara yang multikultural, tidak dapat dipungkiri Indonesia sangat rawan akan konflik horizontal, diskriminasi, dan isu SARA di antara masyarakat. Nanggala (2020) menjelaskan hal tersebut dapat terjadi karena adanya perbedaan pendapat antar pihak dan salah satu contoh yang paling umum adalah perbedaan sikap politik pada saat pemilu. Perbedaan pendapat tersebut dapat diselesaikan dengan komunikasi yang baik, salah satunya dengan musyawarah.

Dengan mengetahui pengaruh konsep tata ruang serta makna setiap elemen rumah gadang dan hubungannya terhadap keberlangsungan fungsi rumah gadang sebagai tempat bermusyawarah diharapkan dapat diketahui seberapa besar pengaruh konsep tata ruang suatu rumah terhadap efektivitas praktek musyawarah dalam masyarakat Indonesia dalam menyelesaikan suatu masalah perbedaan pendapat dan mengambil

keputusan.

\section{METODE PENELITIAN}

Pada penelitian ini, penulis menggunakan metode penelitian studi literatur dan kepustakaan. Proses pengumpulan informasi dilakukan dengan melakukan analisis terhadap literatur jurnal dan buku yang terkait dengan pokok pembahasan.

Penelitian kepustakaan adalah kegiatan penelitian yang dilakukan dengan cara mengumpulkan informasi dan data dengan bantuan berbagai macam material yang ada di perpustakaan seperti buku referensi, hasil penelitian sebelumnya yang sejenis, artikel, catatan, serta berbagai jurnal yang berkaitan dengan masalah yang ingin dipecahkan. Kegiatan dilakukan secara sistematis untuk mengumpulkan, mengolah, dan menyimpulkan data dengan menggunakan metode/teknik tertentu guna mencari jawaban atas permasalahan yang dihadapi. (Sari, M., \& Asmendri, 2020).

Dari hasil penelitian studi literatur dan kepustakaan, penulis dapat menganalisis 
data dan mengambil kesimpulan dari persoalan yang menjadi tema pembahasan.

\section{HASIL DAN PEMBAHASAN}

Rumah gadang merupakan bangunan tradisional dari etnik suku Minangkabau. Secara harfiah, Rumah gadang memiliki arti sebagai "Rumah Besar" dengan bentuk bentuk bangunan berupa persegi panjang dan atap dengan pola berspiral. Rumah gadang digunakan oleh masyarakat Minangkabau sebagai tempat tinggal, aula pertemuan keluarga, dan untuk acara seremonial. Pemilik rumah gadang adalah seorang perempuan dari keluarga yang menempati rumah tersebut dan kepemilikan diturunkan dari ibu kepada anak perempuannya. (Franzia, E., Piliang, Y. A., Saidi, A. I., 2015)

Rumah gadang sudah sangat erat kaitannya dengan etnik suku Minangkabau, namun sulit untuk menemukan referensi yang dapat memberikan informasi mengenai kapan dan bagaimana arsitektur dari rumah gadang mulai digunakan. Namun bukti penggunaan rumah gadang dapat ditelusuri melalui bangunan Istano Basa Pagaruyuang yang merupakan istana dari kerajaan Pagaruyung di Sumetra Utara. Kerajaan Pagaruyung sendiri berdiri sejak tahun 1347 dan runtuh pada tahun 1833 setelah perang Padri. Bangunan Istano Basa Pagaruyuang yang saat ini berdiri merupakan replika dari bangunan lama yang hancur pada abad ke-19.

Rumah Gadang merupakan bentuk perwujudan jenis arsitektur vernacular yaitu bentuk rumah komunal atau sekelompok orang yang tinggal bersama dalam suatu rumah dengan tujuan untuk kebersamaan (Zein, 2017). Dikutip dari Abdullah (2015), Rumah Gadang sejatinya dibangun atas perhitungan rumah ruang dan berjumlah ruangan ganjil. Hal ini menyesuaikan status kepemilikan pemilik rumah. Ukuran rumah diserahkan kepada pemilik rumah namun tetap berpedoman pada tata adat Rumah Gadang Minang.
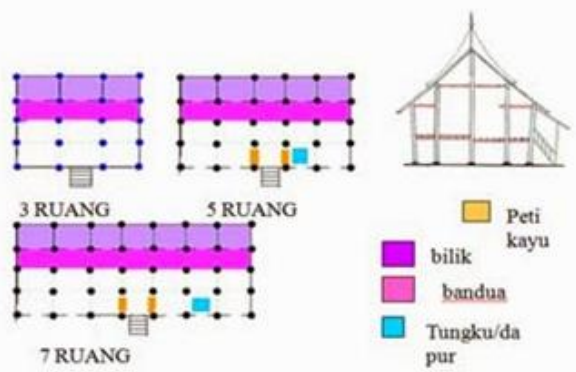

Gambar 1. Denah Asli Rumah Gadang

Pada prakteknya, Rumah Gadang mengalami perunahan desain pola arsitektur. Dimana pada daerah tertentu dan aliran Kato tertentu ditambahkan ruangan seperti anjuang di sisi kanan dan kiri rumah (Salamah, 2020). Anjuang ini bisa terdapat pada kedua sisi rumah seperti pada tipe rumah Rumah Gadang tinggal raja, Rumah Gadangraja, atau hanya terdapat pada satu sisi rumah saja di sisi kanan atau di kiri rumah seperti pada tipe rumah Rumah Gadang rakyat dua (Abdullah, 2015).

Rumah Gadang mempunyai bentuk dan pola denah dari bentuk persegi panjang, hal ini diasumsikan untuk dapat menampung semua aktifitas dan luas untuk ruang gerak. Seluruh ruang dalam rumah gadang merupakan ruang lepas, terkecuali kamar tidur yang disekat dengan dinding pembatas. Bagian dalam terbagi atas lanjar dan ruang, yang ditandai dengan pembatasan tiang (Agus, 1999).

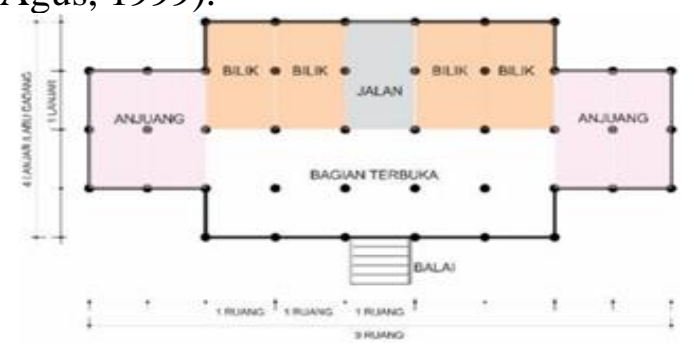

Gambar 2. Rumah Gadang dengan Dua Sisi Anjuang 


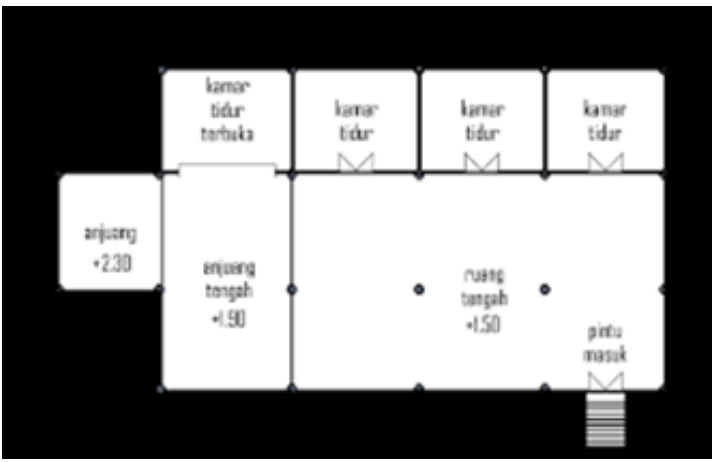

Gambar 3. Rumah Gadang dengan Satu Sisi Anjuang ${ }^{[3]}$

Untuk masuk ke dalam Rumah Gadang, perlu menaiki tangga yang terdapat di bagian tengah. Rumah Gadang yang didesain memanjang, menjadikan pintu Rumah Gadang berada di bagian tengah. Memasuki rumah, terlihat tiang yang menjulang tinggi di seluruh bagian. Terdapat pula lantai yang ditinggikan, dianjuangkan dalam bahasa Minang.

Rumah Gadang memiliki ruang lepas di dalamnya, dari ujung kanan hingga ujung kiri. Sedangkan bagian dari depan ke belakang disebut dengan lanjar. Di bagian lanjar tengah hingga ke belakang, berjejer dari ujung ke ujung kamarkamar yang dihuni oleh perempuan dari anggota keluarga rumah tersebut.

Keluar dari rumah, melalui pintu tengah di bagian belakang. Pintu terletak di antara kamar-kamar yang ada. Terdapat dapur yang terpisah dari rumah utama. Tepatnya, dapur berada di bagian pangkal rumah atau sebelah kiri rumah. Dapur memiliki fungsi yang sama dengan rumah lainnya, sebagai tempat memasak dan makan bagi anggota keluarga. Sedangkan, kamar mandi tidak terdapat di dalam rumah. Zaman dahulu, biasanya kamar mandi berada di alam terbuka, seperti pancuran air atau kolam. Namun sekarang, sudah banyak Rumah Gadang yang dibuatkan kamar mandi khusus di bagian belakang atau di samping rumah.

Rumah Gadang memiliki tata adat asli dimana jumlah ruangan yang terdapat padanya adalah berjumlah ganjil. Hal ini memiliki filosofi tersendiri dimana harus terdapat keseimbangan. Rumah gadang dibuat memanjang, karena didalamnya hidup beberapa keluarga. Jumlah jendela yang banyak dibuat demikian, sehingga membuat sirkulasi udara lebih lancar.

Rumah gadang memiliki ukiran yang menggambarkan kehidupan masyarakat, yang kemudian dipahatkan pada dinding rumah. Pada halaman rumah terdapat rangkiang untuk meyimpan padi. Dalam penerimaan tamu pun diatur secara ketat. Tuan rumah duduk menghadap ke dalam rumah, sedangkan tamu menghadap keluar ke halaman.

Tata ruang rumah gadang terdiri dari $1 / 3$ ruangan untuk ruang tidur, 2/3 ruangan untuk kepentingan umum seperti upacara perkawinan, penobatan kepala suku dan lainnya. Perbandingan ini mempunyai filosofi bahwa kepentingan umum lebih penting daripada kepentingan pribadi.

Ruang tengah menjadi pusat orientasi kegiatan yang bersifat in-door, dimana diruang ini menjadi tempat menjamu tamu, rapat kaum, dan juga tempat makan. Dari ruang tengah alur gerak diarahkan ke bilik-bilik (kamar tidur) dan juga untuk kedapur di bagian belakang. Setiapa lanjar atau ruang mempunyai fungsi tetentu. Dimana diatur dalam tambo dan juga adat istiadat yang berlaku. Dimana hal ini mencerminkan adanya norma yang mengatur demi ketertiban bersama (Agus, 2015).

Selain itu Rumah gadang terkenal dengan kekokohannya dalam mengahadapi guncangan. Hal ini disebabkan oleh arsitektur dari Rumah Gadang yang didesain tahan guncangan. Rumah Gadang memiliki tiang yang tidak lurus atau vertikal tapi punya kemiringan. Tiang penyangga rumah gadang yang menyerupai kapal. Di setiap tiang-tiang Rumah Gadang diletakkan sandi (batu yang cukup besar 
dan rata bagian atasnya) sebagai penyangga antara tiang dengan tanah. Sandi ini tempat berdirinya tiang-tiang utama Rumah Gadang, sehingga secara tidak langsung goyangan (getaran) mendatar di tanah tidak langsung dirasakan pada tiang bangunan. Jika terjadi gempa akan bergoyang atau berayun saja dan menahan rumah untuk tidak roboh (Habibi, 2018).

Pada bagian Filosofis sudah dijabarkan bahwa, tata ruang rumah gadang terdiri dari $1 / 3$ ruangan untuk ruang tidur, $2 / 3$ ruangan untuk kepentingan umum. Rumah gadang merupakan bangunan pusat dari seluruh anggota kaum dalam membicarakan masalah mereka bersama. Segala permasalahan berkaitan dengan keluarga, masyarakat dan kaum dipecahkan bersama melalui mufakat.

Pada aliran Minagkabau Bodi Caniago, dipimpin Datuk Perpatih Nan Sabatang, pelaksanaan kegiatan adat dilandaskan atas azas demokrat, dimana segala sesuatunya dimusyawarahkan dulu untuk mencapai mufakat (bottom-up), tak terdapat lapisan-lapisan seperti kasta dalam masyarakat, karena memang semua kita mempunyai hak sama. Hal ini lah salah satu alasan pembuatan ruang telangah Rumah Gadang yang digunakan untuk kepentingan umum, serta bentuk pelaksanaan demokrasi dimana untuk mengambil keputusan sebelumnya harus dilaksanakan terlebih dahulu musyawarah hingga mencapai mufakat.

\section{KESIMPULAN DAN SARAN}

Masyarakat Minangkabau adalah masyarakat yang sangat menjunjung tinggi musyawarah dan kepentingan bersama. Hal tersebut tercermin dari tata ruang rumah adat Minangkabau atau biasa disebut rumah gadang. Sebagian besar ruangan pada rumah gadang adalah rumah lepas. Ruang lepas ini bertujuan untuk mendukung kegiatan- kegiatan sehari-hari maupun kegiatan adat masyarakat Minangkabau, salah satunya adalah musyawarah untuk mufakat.

Seperti yang telah diketahui dalam konsep demokrasi Indonesia, musyawarah memiliki peran yang sangat penting. Pada praktiknya, keberlangsungan musyawarah di masyarakat memerlukan fasilitas dan lingkungan yang mendukung. Oleh karena itu, dalam membangun bangunan untuk umum ataupun pribadi perlu memerhatikan desain denah ruangan agar mendukung diadakannya musyawarah seperti mengikuti tata ruang rumah gadang. Tata ruang yang sesuai dan mendukung akan meningkatkan efektivitas proses musyawarah.

Penelitian yang kami lakukan masih memiliki banyak keterbatasan dari segi pengumpulan data karena hanya mengandalkan studi literatur dan kepustakaan. Diperlukan data penelitian lebih lanjut berupa observasi dan pengamatan terhadap rumah gadang secara langsung dan juga wawancara terhadap warga lokal yang mendiami rumah gadang untuk mendapatkan data yang lebih akurat dan relevan dengan permasalahan yang kami bahas pada penelitian ini.

\section{DAFTAR PUSTAKA}

Abdullah, Maulana., (2015). Pola Ruang Dalam Bangunan Rumah Gadang Di Kawasan Alam Surambi Sungai Pagu - Sumatera Barat. Universitas Brawijaya

Agus, Elfida., (2015). Kajian Topologi, Morfologi Dan Tipologi Pada Rumah Gadang Minangkabau. Univeritas Bung Hatta. 
Amelia, Z. Y., (2019). Perkembangan Islam Di Kesultanan Pagaruyung. Universitas Sriwijaya, Indonesia.

Franzia, E., Piliang, Y. A., Saidi, A. I., (2015). Rumah Gadang as a Symbolic Representation of Minangkabau Ethnic Identity. International Journal of Social Science and Humanity, Vol. 5, No. 1.

Habibi, Gantino., (2018). Rumah Gadang yang Tahan Gempa. Jakarta: Badan Pengembangan dan Pembinaan Bahasa, Kementerian Pendidikan dan Kebudayaan.

Hanafi, Muhammad. "Kedudukan Musyawarah dan Demokrasi di Indonesia." Jurnal Cita Hukum, vol. 1, no. 2, 2013, doi:10.15408/jch.v1i2.2657.

Malik, R. (2016). Ikatan Kekerabatan Etnis Minangkabau dalam Melestarikan Nilai Budaya Minangkabau di Perantauan sebagai Wujud Warga NKRI. Jurnal Analisa Sosiologi, 17-27.

Marthala, A. E. (2013). Rumah Gadang:

Kajian Filosofi Arsitektur Minangkabau. Bandung: Humaniora.

Munir, Miznar. dkk., (2015). Filosofi Rumah Gadang Minangkabau. Fakultas Filsafat, Universitas Gadjah Mada.

Muzaqqi, F. (2012). Musyawarah Mufakat: Gagasan dan Tradisi Genial. Jurnal Politik Indonesia, 1(2), 73-82.

Nanggala, A. (2020). Pendidikan Kewarganegaraan Sebagai
Pendidikan Multikultural. Jurnal Soshum Insentif, 3(2), 197-210. Salamah, Hafsah., \& Feni Kurniati., (2020). Prespektif Struktur dan Konstruksi pada Proses Renovasi Rumah Gadang. . IPLBI 4, 065 063, Februari 2020

Sari, M., \& Asmendri, (2020). Penelitian Kepustakaan (Library Research) dalam Penelitian Pendidikan IPA. Natural Science: Jurnal Penelitian Bidang IPA Dan Pendidikan IPA, 6, 41-53.

Zein, Anastasha., (2017). Ruang Komunal Pada Arsitektur Vernakular Uma, Lamin, \& Rumah Gadang. Jurnal ATRAT V5/N3/09/2017. 